\title{
Inhibitory Effect of Isodon Diterpenoids on Growth and Mitochondrial Oxidative Phosphorylation in Lepidopterous Insects
}

\author{
Makoto Taniguchi, Masanori YamaguChI, Isao KUBo* \\ and Takashi KuBotA** \\ Faculty of Science, Osaka City University, Osaka 558 \\ *Department of Chemistry, Columbia University, New York, N. Y. 10027 \\ **School of Medicine, Kinki University, Sayama-cho, Osaka 589
}

Received July 17, 1978

\begin{abstract}
The diterpenes from the plants of the genus Isodon (Labiatae) exhibited a relatively specific growth inhibitory activity against lepidopterous larvae. The $\alpha$-methylene cyclopentanone moiety (D-ring) was essential for this activity. In addition, these compounds strongly inhibited the oxidative phosphorylation in mitochondria isolated from silkworm midgut.
\end{abstract}

A number of bitter ent-kaurenoid diterpenes have been isolated from the plants of the genus Isodon (Labiatae). ${ }^{1,2}$ These compounds possess a specific antimicrobial activity against gram positive bacteria, cytotoxic activity against KB tissue culture and inhibitory activity on oxidative phosphorylation in rat liver mitochondria..$^{3,4}$ These bitter principles contain, as a major structural feature, an $\alpha$-methylene cyclopentanone moiety (D-ring), which apparently is essential for their biological activity since all their dihydro-derivatives are entirely inactive. However, this moiety has little direct relationship to the bitter taste. We have proposed a qualitative theory to relate the bitter taste of these compounds to their chemical structure..$^{5)}$ For a compound in this series to taste bitter, it must contain at least one "bitter unit," where the bitter unit consists of hard acid (HA) and hard base (B) moieties positioned so they can form an intramolecular hydrogen bond. In our recent studies of chemical factors in various plants resistant to the larvae of the African army worm, Spodoptera exempta, we have found that the Isodon bitter diterpenoids show moderate antifeeding activity in a "choice" test and relatively specific growth inhibitory activity in a "non-choice" test. Their bitter dihydro-derivatives still show antifeeding activity but no growth inhibitory activity.

In the present paper, inhibitory activity of these diterpenes toward lepidopterous insects was investigated in reference to the growth and mitochondrial oxidative phosphorylation.

\section{MATERIALS AND METHODS}

Diterpenoids. The Isodon diterpenoids and their dihydro-derivatives used in this study were all analytically pure samples obtained from our previous studies. $^{6 \sim 10)}$ The selection of these compounds was based mainly upon the availability of the samples as well as their characteristic structural types.

Insects. The larvae of the African army worm, Spodoptera exempta, were taken from standard stock cultures, which were reared throughout the year in the International Centre of Insect Physiology and Ecology, Nairobi, Kenya. The monophagous, $S$. exempta is well known as a major graminaceous crop pest in East and South Africa.

The larvae of the silkworm, Bombyx mori of the $F_{1}$ hybrid between two races, Showa and Kinshu, were supplied by Otsuka Pharmaceutical Co., Ltd.

Feeding and growth tests. Antifeeding and growth inhibitory activities against the third instar larvae of army worm were tested by the leaf disk method with Zea mays, a normal food-plant for $S$. exempta. ${ }^{11)}$ Leaf disks, $20 \mathrm{~mm}$ in diameter, were punched out with a cork borer. Test disks were immersed for 2 seconds in an acetone solution of the sample. Control disks were immersed only in acetone. The disks were then dried in air. Five test and five control disks were placed in a Petri dish with ten third instar larvae. This constituted a "choice" test, whereas deletion of the control disks constituted a "non-choice" test. 
Growth test on the third instar larvae of silkworm was conducted according to the method described by Murakoshi et al. ${ }^{12}$ )

Preparation of mitochondrial suspensions. Midgut tissues were collected from the fourth instar larvae of silkworm and the peritrophic membrane containing the midgut content was removed. ${ }^{13)}$ The resultant tissues were washed and homogenized with an ice-cold solution of $150 \mathrm{~mm} \mathrm{KCl}$ and $1 \mathrm{~mm}$ EDTA in a PotterElvehjem homogenizer. The homogenate was centrifuged at $150 \times g$ for $3 \mathrm{~min}$, and the supernatant again centrifuged at $8000 \times g$ for $8 \mathrm{~min}$. The sedimented mitochondrial pellet was rinsed once and suspended in the same solution.

Protein content of the mitochondrial suspensions was determined by the biuret reagent after the addition of an equal volume of $5 \%$ Triton $\left.X-100,{ }^{14}\right)$ bovine serum albumin being used as a standard.

Measurement of mitochondrial oxidative phosphorylation activity. The reaction mixture contained $30 \mathrm{~mm}$ $\mathrm{K}_{2} \mathrm{HPO}_{4}, 50 \mathrm{mM}$ Tris- $\mathrm{HCl}, 15 \mathrm{mM} \mathrm{KCl}, 5 \mathrm{mM} \mathrm{MgCl} \mathrm{Mg}_{2}$. $6 \mathrm{H}_{2} \mathrm{O}, 2 \mathrm{mM}$ EDTA, test compound, $0.8 \sim 0.9 \mathrm{mg}$ of mitochondrial protein, $20 \mathrm{~mm}$ pyruvate and $10 \mathrm{~mm}$ malate in a total volume of $2 \mathrm{ml}$ at $\mathrm{pH} 7.5$.

Oxygen consumption was measured polarographically with a Yanagimoto PO-100A oxygen electrode equipped with a $Y \mathbf{R}-101 \mathrm{P}$ chart recorder, Oxidative phosphorylation activity was calculated from the oxygen electrode tracings ${ }^{15}$ ) and expressed as a respiratory control ratio and an $\mathrm{ADP} / \mathrm{O}$ ratio. The phosphorylation rate was calculated as the $A D P / O$ ratio $\times$ the rate of respiration in State 3 .

\section{RESULTS AND DISCUSSION}

The antifeeding and growth inhibitory activities of several Isodon diterpenes $(1 \sim 5)$ as well as their dihydro-derivatives $(6 \sim 10)$ have been tested against the third instar larvae of the African army worm. All compounds which taste bitter to humans ${ }^{5,16}$ prevented feeding for at least $2 \mathrm{hr}$ at $100 \mathrm{ppm}$ concentration (ca. $2 \mu \mathrm{g} / \mathrm{cm}^{2}$ leaf disk) in a "choice" test. However, at this concentration none of these bitter compounds showed antifeeding activity after $24 \mathrm{hr}$ in a "non-choice" test. Isodonal (1) and enemin (2) showed only $50 \%$ antifeeding activity even at $1000 \mathrm{ppm}$ concentration ( $c a$. $20 \mu \mathrm{g} / \mathrm{cm}^{2}$ leaf disk) after $24 \mathrm{hr}$. The major portion $(>80 \%)$ of the treated disk was eaten under conditions of severe starvation. However, even when the larvae were returned to normal diet after eating the treated disk, their growth was strongly inhibited and they eventually died. The effect of these compounds was assessed either by weight loss or by reduced rate of weight gain as compared with controls (Fig. 1), as well as by the number of deaths. Interestingly, the $\alpha$-methylene cyclopentanone moiety (D-ring) was an essential structural feature for this activity since reduction of the methylene group caused loss of the activity.

Recently Hosozawa et al. have proposed the term of "relative antifeedant" to the antifeeding substance which retards feeding over a defined time and, after this defined time, quickly loses the antifeeding activity. ${ }^{17}$ ) It seems therefore that this term may be used to describe the Isodon bitter substances. However, it should be noted that antifeedants, as defined, do not directly kill insects. ${ }^{18}$ Thus, these diterpene compounds are, in fact, growth

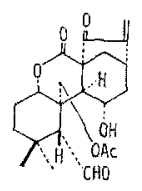

(1)

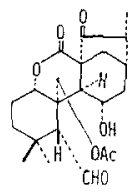

(6)

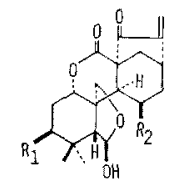

(2) $\mathrm{R}_{1}=0 \mathrm{H}, \mathrm{R}_{2}=\mathrm{H}$

(3) $R_{1}=\mathrm{H}, R_{2}=\mathrm{OH}$

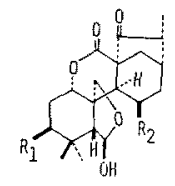

(7) $\mathrm{R}_{1}=\mathrm{OH}, \mathrm{R}_{2}=\mathrm{H}$

(8) $R_{1}=H_{s} R_{2}=$ OH

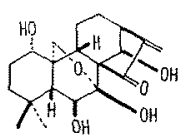

(4)

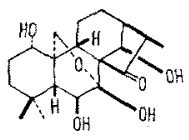

(9)

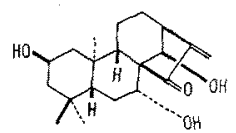

(5)

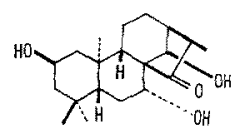

(10) 


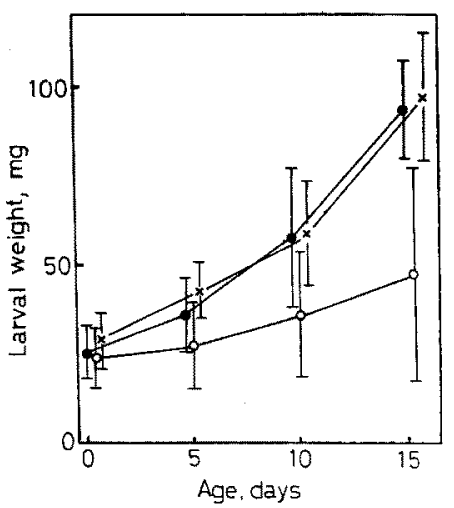

Fig. 1. Effect of Isodonal (1) and Dihydroisodonal (6) on the Growth of S. exempta.

In a "non-choice" test, weight of surviving larvae was measured during the period just before control larvae begin to pupate. Each point is mean with S. D. (bar) of 10 insects. $x-x$, control; $O-0,100 \mathrm{ppm}$ isodonal (1);- $100 \mathrm{ppm}$ dihydroisodonal (6).

inhibitors or biological poisons. These diterpenes appear to act slowly since the larvae consume more than 20 times the lethal dose (oral $\mathrm{LD}_{100} 1 \sim 10 \mu \mathrm{g}$ per insect) before becoming unable to feed. Similar toxic effect was also observed on the third instar larvae of the silkworm (oral $\mathrm{LD}_{100} 0.1 \sim 1 \mu \mathrm{g}$ per insect).

These compounds did not affect the feeding behavior of many other insects (e.g., the housefly, Musca domestica and the antesia bug, Antestiopsis $\left.s p p^{19}\right)$. The growth inhibitory properties seem relatively specific for lepidopterous larvae.

Recently we have reported that these diter- penoids show an inhibitory effect on some energy-linked functions in rat liver mitochondria and the $\alpha$-methylene cyclopentanone moiety is also essential for this effect. ${ }^{4}$ Accordingly, it is of interest to examine the effect of these compounds on the mitochondrial functions of lepidopterous larvae to understand the biochemical aspects involved. The silkworm midgut was used as a lepidopterous mitochondrial source because its mitochondria were relatively stable.

As shown in Table I, these diterpenes ( $1 \sim 4)$, at a concentration of $250 \mu \mathrm{M}$, strongly inhibited the mitochondrial oxidative phosphorylation activity (expressed both as a respiratory control ratio and an $\mathrm{ADP} / \mathrm{O}$ ratio) and the phosphorylation rate. This may indicate that the growth inhibition by these compounds in lepidopterous insects occurs through the inhibitory action on mitochondria.

These compounds significantly depressed the rate of respiration in State 3 and in 2,4dinitrophenol uncoupled mitochondria (State $4 U)$, though hardly affected or only a little stimulated that in State 4. Thus, they seem to act neither as an uncoupler (e.g., 2,4-dinitrophenol) nor as a phosphorylation inhibitor (e.g., oligomycin), because the former markedly stimulates the respiratory rate in State 3 and State 4, while the latter inhibits the respiratory rate in State 3 but shows no effect in State 4 and State $4 \mathrm{U}$. These diterpenoids seem to have an action on the respiratory chain enzymes

Table I. Effect of Diterpenotds on Oxidative Phosphorylation Activity in Mrtochondria Isolated from Silkworm Midgut

\begin{tabular}{|c|c|c|c|c|c|c|}
\hline \multirow{3}{*}{ Compounds ${ }^{a}$} & & iratory & & \multirow{3}{*}{$\begin{array}{c}\text { Respiratory } \\
\text { control } \\
\text { ratio }\end{array}$} & \multirow{3}{*}{$\mathrm{ADP} / \mathrm{O}$} & \multirow{3}{*}{$\begin{array}{c}\text { Phosphory- } \\
\text { lation } \\
\text { rate }^{d}\end{array}$} \\
\hline & \multicolumn{3}{|c|}{ State } & & & \\
\hline & 3 & 4 & $4 \mathrm{U}^{e}$ & & & \\
\hline Control & 85.6 & 21.3 & 102.7 & 4.02 & 2.21 & 189 \\
\hline Isodonal (1) & 40.9 & 23.8 & 55.2 & 1.72 & 1.09 & 45 \\
\hline Enemin (2) & 71.6 & 22.5 & 91.6 & 3.18 & 1.61 & 115 \\
\hline Nodosin (3) & 54.9 & 25.2 & 74.6 & 2.18 & 1.40 & 77 \\
\hline Oridonin (4) & 65.4 & 23.6 & 90.3 & 2.77 & 1.61 & 105 \\
\hline \multicolumn{7}{|c|}{ a The final concentration of each compound was $250 \mu \mathrm{M}$. } \\
\hline \multicolumn{7}{|c|}{${ }^{b} \quad$ Expressed as natoms $\mathrm{O} / \mathrm{mg}$ protein $/ \mathrm{min}$. } \\
\hline \multicolumn{7}{|c|}{. In the presence of 2,4-dinitrophenol at $50 \mu \mathrm{M}$. } \\
\hline \multicolumn{7}{|c|}{$d$ Expressed as nmoles ATP synthesized/mg protein/min. } \\
\hline
\end{tabular}


similar to that of cyanide, rotenone and antimycin A, although detailed studies on the site of action are needed.

We have previously reported that the $a$ methylene cyclopentanone moiety of these diterpenoids has a high reactivity toward sulf hydryl groups. ${ }^{2,3,20)}$ Also, recent reports show that sulfhydryl groups in the mitochondrial membrane are largely responsible for energylinked functions. ${ }^{21 \sim 23)}$ It seems, therefore, to be of interest to investigate whether these diterpenoids directly affect the function of respiratory chain enzymes in which sulf hydryl groups play an important role. Their antimicrobial and antitumor activities may also have a close relation to inhibition in the respiratory chain, as in the case of insect growth inhibitory activity.

Acknowledgements. This work was initiated during the stay of $\mathbf{I}$. Kubo at the International Centre of Insect Physiology and Ecology (ICIPE), Nairobi, Kenya. A grant to I. Kubo from the Japan Society for the Promotion of Science is gratefully acknowledged. We are grateful to Mr. A. Chapya, ICIPE for technical assistance. We also thank Otsuka Pharmaceutical Co., Ltd., for gifts of the larvae of the silkworm.

\section{REFERENCES}

1) E. Fujita, Y. Nagao and M. Node, Heterocycles, 5, 793 (1976) and references cited therein.

2) I. Kubo, M. Pettei, K. Hirotsu, H. Tsuji and T. Kubota, J. Am. Chem. Soc, 100, 628 (1978).

3) I. Kubo, M. Taniguchi, Y. Satomura and T. Kubota, Agric. Biol. Chem., 38, 1261 (1974).

4) M. Yamaguchi, M. Taniguchi, I. Kubo and T. Kubota, ibid., 41, 2475 (1977).

5) T. Kubota and I. Kubo, Nature, 223, 97 (1969).

6) I. Kubo, T. Kamikawa and T. Kubota, Tetrahe- dron, 30, 615 (1974).

7) T. Kubota, M. Matsuura, T. Tsutsui, S. Uyeo, H. Irie, A. Numata, T. Fujita and T. Suzuki, ibid., 22, 1659 (1966).

8) E. Fujita, T. Fujita and M. Shibuya, Chem. Pharm. Bull., 16, 509 (1968).

9) E. Fujita, T. Fujita, H. Katayama, M. Shibuya and T. Shingu, J. Chem. Soc. C., 1970, 1674.

10) I. Kubo, T. Kamikawa, T. Isobe and T. Kubota, Bull. Chem. Soc. Jpn., 47, 1277 (1974).

11) I. Kubo and K. Nakanishi, in "ACS Symposium Series 62, Host Plant Resistance to Pests," ed. by P. A. Hedin, American Chemical Society, Washington, D. C., 1977, p. 165.

12) S. Murakoshi, T. Nakata, Y. Otuka, H. Akita, A. Tahara and S. Tamura, Jap. J. Appl. Ent. Zool., 19, 267 (1975).

13) R. S. Travers and R. M. Faust, J. Invertebr. Pathol., 28, 351 (1976).

14) A. G. Gornall, C. T. Bardawill and M. M. David, ibid., 177, 574 (1953).

15) R. W. Estabrook, in "Methods in Enzymology," Vol. X, ed. by R. W. Estabrook and M. E. PulIman, Academic Press Inc., New York, N. Y, 1967, p. 41.

16) I. Kubo and T. Kubota, J. Food Chem., in press.

17) S. Hosozawa, N. Kato and K. Munakata, Agric. Biol. Chem., 38, 823 (1974).

18) K. Wada and K. Munakata, J. Agric. Food Chem., 16, 471 (1967).

19) We are grateful to Prof. T. Ohtaki, Kanazawa University, for this bioassay.

20) E. Fujita, Y. Nagao, K. Kaneko, S. Nakazawa and H. Kuroda, Chem. Pharm. Bull., 24, 2118 (1976).

21) N. Sabadie-Pialoux and D. Gautheron, Biochim. Biophys. Acta, 234, 9 (1971).

22) E. Bäuerlein and T. Wieland, in "Biochemistry and Biophysics of Mitochondrial Membrane," ed. by G. F. Azzone, E. Carafoll, A. L. Lehninger, E. Quagliariello and N. Siliprandi, Academic Press Inc., New York, N. Y., 1972, p. 389.

23) E. A. Ivancheva and E. M. Rusanov, Dokl. Bolg. Akad. Nauk., 28, 975 (1975). 